\title{
Crisis-Specific Peer Supervision of School Counselors: The P-SAEF Model
}

\author{
By: Carrie A. Wachter, Casey A. Barrio Minton, Elysia V. Clemens
}

Wachter, C. A., Barrio Minton, C. A., \& Clemens, E. V. (2008). Crisis specific supervision of school counselors: The P-SAEF Model. Journal of Professional Counseling: Practice, Theory, and Research, 36(2), 13-24.

Made available courtesy of Texas Counseling Association: https://www.txca.org

***:(C) Texas Counseling Association. Reprinted with permission. No further reproduction is authorized without written permission from Texas Counseling Association. This version of the document is not the version of record. Figures and/or pictures may be missing from this format of the document. $* * *$

Abstract:

School counselors are called upon to respond to an array of crisis situations involving the potential for imminent harm. Many school counselors report inadequate preparation for crisis intervention (Allen et al., 2002; King et al., 1999), and few school counselors participate in clinical supervision (Page et al., 2001). P-SAEF, a practical peer supervision model for school counselors who work with students at risk for imminent harm, is presented, and recommendations for implementation are provided.

Keywords: secondary school students | academic guidance counseling | violence | suicides | suicide attempts | counselor education | school counselors | crisis intervention | intervention | imminent harm

\section{Article:}

School counselors are called upon to respond to an array of crisis situations involving the potential for imminent harm. Many school counselors report inadequate preparation for crisis intervention (Allen et al., 2002; King et al., 1999), and few school counselors participate in clinical supervision (Page et al., 2001). P-SAEF, a practical peer supervision model for school counselors who work with students at risk for imminent harm, is presented, and recommendations for implementation are provided.

As leaders in crisis response, school counselors must develop and implement plans that meet students' immediate needs through short-term counseling, referrals, and consultation with stakeholders (American School Counselor Association [ASCA], 2000, 2005). Although school counselors have a responsibility to practice within their individual competencies (ASCA, 2004) there appears to be a substantial disconnect between preparation and expectations faced in the schools. Allen and colleagues (2002) found that 35\% of school counselors reported receiving no training in crisis intervention in their graduate education, and 57\% of school counselors surveyed felt either not at all or minimally prepared for crisis intervention. Although the Centers for Disease Control and Prevention [CDC] (2006) estimated that 16.9\% of high school students 
seriously considered attempting suicide and $8.4 \%$ of students attempted suicide in the past year, King, Price, Telljohann, and Wahl (1999) reported that only 38\% of school counselors believed they could recognize a student at risk for suicide. Wachter (2006) also found that counselors in school settings reported similar experiences with suicidal students; nearly $30 \%$ reported no master's level training on issues of suicide.

Just as suicidality is anything but rare in a school setting, the CDC (2006) reported that over $18.5 \%$ of high school students had carried a weapon in the past month and over one- third had been in a physical fight in the past year. Considering that $91 \%$ of public secondary schools, $90 \%$ of public middle schools, and $60 \%$ of public elementary schools reported acts of violence over a twelve month period, the vast majority of school counselors will be faced with violence on school grounds (DeVoe et al., 2004). Unfortunately, nearly $70 \%$ of school counselors reported having no training in school violence or gang violence (Wachter, 2006).

Crisis situations have a powerful effect on clinicians of all experience levels (Kleespies, Niles, Mori, \& Deleppo, 1998), and even experienced counselors desire additional preparation and support when faced with crises (Mathai, 2002; Tracey, Ellickson, \& Sherry, 1989). Regardless of prior preparation and experience, crisis specialists stress the importance of education, debriefing, and supervision on issues involving imminent harm (e.g., Kinzel \& Nanson, 2000; Westefeld et al., 2000). Although participation in supervision may remedy lack of preparation, ensure client safety, and support the well-being of counselors, low rates of school counselor participation in clinical supervision (Page, Pietrzak, \& Sutton, 2001) present unique challenges for ensuring school counselor competence. In the following pages, we explore literature regarding supervision of school counselors and present an innovative model for crisis-specific school counselor peer supervision.

\section{Supervision of School Counselors}

Clinical supervision is important for the professional development of school counselors (e.g., Miller \& Dollarhide, 2006; Page et al, 2001; Wood \& Rayle, 2006). Participation in supervision enhances client safety, counselor effectiveness, and counselor well-being; not participating in supervision may negatively impact school counselors' use of essential helping skills (Crutchfield \& Borders, 1997; Peace, 1995). Despite the substantive benefits of supervision, the of school counselors who participate in clinical supervision remains very low (Page et al.).

In light of continuing struggles to involve school counselors in clinical supervision, several experts identified peer supervision as a viable option for the development of school counselors (Benshoff \& Paisley, 1996; Crutchfield \& Borders, 1997). Wilkerson (2006) defined peer supervision as:

...a structured, supportive process in which counselor colleagues... in pairs or in groups, use their professional knowledge and relationship expertise to monitor practice and effectiveness on a regular basis for the purpose of improving specific counseling, conceptualization, and theoretical skills, (p. 62) 
Higher rates of participation in peer supervision indicate that it may be a more practical option for school counselors (Wilkerson, 2006), and recent findings indicate that peer supervision is beneficial for school counselors. In particular, availability of Peer supervision was related to decreased role stress (Culbreth, Scarborough, Banks-Johnson, \& Solomon, 2005) and enhanced career satisfaction among practicing school counselors (Baggerly \& Osborn, 2006).

Existing general peer supervision models (e.g., Agnew, Vaught, Getz, \& Fortune, 2000; Crutchfield \& Borders, 1997; Thomasgard \& Collins, 2003) provide guidance for structuring time, defining roles and relationship, and giving feedback. These models are designed to address all counseling duties of professional school counselors and are not specific to responsive services involving imminent harm. However, specific elements of peer supervision are especially promising for crisis-specific supervision. Peers within the same school district are likely to follow similar policies for crisis response and have access to similar resources, which may lend well to preparation for and reflection upon crisis intervention, Furthermore, peer supervision may increase the knowledge and skills needed to respond effectively to similar situations. Next, we provide a crisis-specific peer supervision model for school counselor intervention in cases of imminent harm. This model builds upon the existing literature on peer supervision and provides school counselors with a concrete framework for supporting each other as they learn about crisis response and ensure student safety.

\section{The P-SAEF}

Because we were unable to locate any literature specific to peer supervision of school counselors in instances of crisis, we developed a model to guide crisis-specific peer supervision. This model, abbreviated P-SAEF, incorporates Preparation and training, Safety of client, Affective support for the supervisee, Evaluation and walkthrough, and Follow-up planning. This model has been developed to be useful to practicing school counselors at all levels of experience and can be adapted for clinical supervision of interns.

Preparation and Training

To participate in this model as a peer supervisor, the school counselor must have content and skill knowledge regarding crises of imminent harm and supervision practices. These areas of preparation are vital for prevention of crises and effective intervention and supervision after a crisis of imminent harm has occurred, Individual preparation needs are likely to be specific to one's knowledge and experience, and assessment of specific crisis-related and supervision competencies are the first step in this model. Figure 1 contains prompts school counselors may use to self-assess knowledge and skills related to a crisis. 


\section{Figure 1. Self-assessment of crisis preparation}

Do I know...

- Risk factors for suicidality

- Risk factors for homicidality

- Risk factors for violence

- Proper response to overdoses on medication or household substances

- My school's crisis response plan

- Local referral resources including each of the following: 24-hour hotlines, crisis shelters, outpatient programs, intensive outpatient programs, inpatient crisis stabilization programs

- Procedures for maintaining student safety on school grounds

- Procedures for initiating hospitalizations, both voluntary and involuntary

- Procedures for involving emergency personnel

- Potential ethical and legal concerns

- Risks of using no-harm contracts
Could I...

- Conduct a suicide assessment

- Conduct a violence assessment

- Conduct a mental status exam

- Enact my school's crisis response plan

- Facilitate creation of an individualized crisis response plan

- Match students with appropriate referrals

- Help parents or guardians understand how to keep their child safe, including the following: clear instruction on hospitalization procedures, location of referral resources, what to expect from community resources

- Communicate with another mental health professional using clinical or diagnostic language

- Instruct teachers on how to make appropriate referrals

- Involve necessary school personnel while maintaining appropriate privacy

The preparation and training stage of the P-SAEF model is well-suited to peer group supervision; a peer group may advocate for district support to attend existing seminars or workshops about supervision best practices, or group members may research and provide crisis specific in-service training for colleagues, Additional crisis preparation activities may include visiting the local crisis center, developing a referral database, and practicing suicide or violence assessment skills, School counselors may find that roleplaying intervention skills will help reduce anxiety and discomfort experienced during a crisis; similarly, practicing supervision skills on non-crisisoriented cases may help novice supervisors feel more comfortable. Armed with knowledge and skills, school counselors can know when and how to initiate procedures to protect the safety of their students. 
Ideally, school counselors would be thoroughly prepared prior to being called upon to provide crisis intervention, but this may not always be possible. The next segments of the P-SAEF model address post-crisis debriefing and follow-up for school counselors regardless of experience and expertise.

\section{Safety of Client}

The safety component of the P-SAEF model begins at the time of crisis. Client safety is a primary goal of supervision (Bernard \& Goodyear, 2004), and ensuring safety is especially important in potentially harmful situations. When a peer apprises a peer supervisor of an incident, the supervisor must first ensure that the client's safety has been secured, For example, in the case of an intentional overdose at school, a supervisor would ensure that district procedures for medical evaluation and referral have been activated.

Supervisors can draw upon their knowledge base regarding crisis intervention and school district policies to their assessment of client safety. Key aspects to consider include the student's current level of physical safety, plans for maintaining safety, and ability of parents/guardians and other appropriate adults to facilitate appropriate response. It is imperative to remind supervisees that while a student may appear healthy physically there may be pressing medical needs that require immediate attention, Regardless of suicidal intent, self-injurious behavior or inappropriate ingestion of any potentially harmful substance is likely to warrant immediate medical attention.

\section{Affective Support}

Crisis situations are intense, and frequent exposure to those in pain is a risk factor for burnout in helping professionals (Fong, 2005; Schaufeli, Marek, \& Maslach, 1993). This portion of the PSAEF model is designed to help peer supervisors provide the intervening school counselor with affective support to provide a protective factor against burnout. The inclusion of support as a distinct component of the peer supervision process is intended to normalize counselors' emotional responses and model self-care as integral in the postvention experience.

Affective support should occur within hours to several days of the crisis and may consist of an informal debriefing with a focus on the school counselor's internal response. The supervisor may attend to the supervisee's self-perceptions regarding support necessary to feel emotionally settled enough to engage in the critical thinking aspects of supervision that will follow. In cases where supervisees experience difficulty controlling anxiety related to the crisis, peer supervisors may assist their supervisees by engaging them in relaxation exercises.

\section{Evaluation and Feedback}

Once the student's safety has been assured and the counselor has been provided with affective support, focus of supervision turns to evaluation and feedback. Timing for this step is flexible; however, peers may find that recall is more accurate within several days of the intervention. Although provision of honest feedback can be a difficult in peer relationships (Benshoff \& Paisley, 1996), the evaluative component is a critical aspect of supervision (Wilkerson, 2006). The evaluative walk- through includes four important components. First, processing what went 
well may reinforce behaviors and decisions that were effective. Second, the peer supervisor and school counselor need to speak frankly about what could have been done better. The identification of mistakes and feedback about potential consequences serve as teachable moments to improve crisis intervention practices, Third, the school counselor and peer supervisor should process obstacles that impeded the intervention process. These could be structural (e.g., out-of-date crisis plan), behavioral (e.g., not calling poison control), cognitive (e.g., lack of knowledge about dangers posed by extended-release medications), or affective (e.g., feelings of powerlessness). Identification of obstacles can help prevent or minimize the effects of similar obstacles in the future. Finally, the peer supervisor and school counselor should process anything that happened that the counselor was not expecting. This combination of feedback and collaborative processing assists supervisees' self-reflection as they broaden their vision regarding dynamics that may arise in the next crisis.

\section{Follow-up Planning}

The final stage of the P-SAEF model includes a three-pronged approach to follow-up planning. This can occur immediately after the Evaluation and Walkthrough phase and be revisited periodically as supervisee and site needs shift, First, the peer supervision dyad or group should identify needs and facilitate follow-up services for those directly involved in the crisis. A formal plan will help guide the counselor's next steps with those involved and will also be a way to ensure client welfare after the crisis is stabilized. For example, the school counselor might make plans for regular check- ins with the student and refer the student for mental health counseling with an outside provider. Next, the supervisor and school counselor should attend to appropriate follow-up support services for the family and close friends of the individuals directly affected by the crisis. In this stage, follow-up might involve touching base with close friends, siblings, and family of an adolescent who attempted suicide to provide services or resources for support, Finally, follow-up planning should include attention to administrative or organizational actions that may facilitate healing, prevent similar crises, or promote more effective crisis response. The crisis plan might need to be rewritten or revised to incorporate new information. Additional training, in-services, or support may be offered to faculty and staff to ensure they have information and skills necessary to facilitate referrals to the school counselor.

\section{Cyclical Nature of P-SAEF}

The P-SAEF model is depicted in Figure 2. As noted in the figure, this model is both linear and cyclical in nature. Although it is designed as a step-by-step process, each of the steps will inform further Preparation and Training needs. For example, in the Affective Support phase, a school counselor might identify an area for personal growth or reflection. In the Evaluation and Walkthrough phase, gaps in knowledge or skills that need to be addressed may be identified. 


\section{Figure 2. The P-SAEF model}

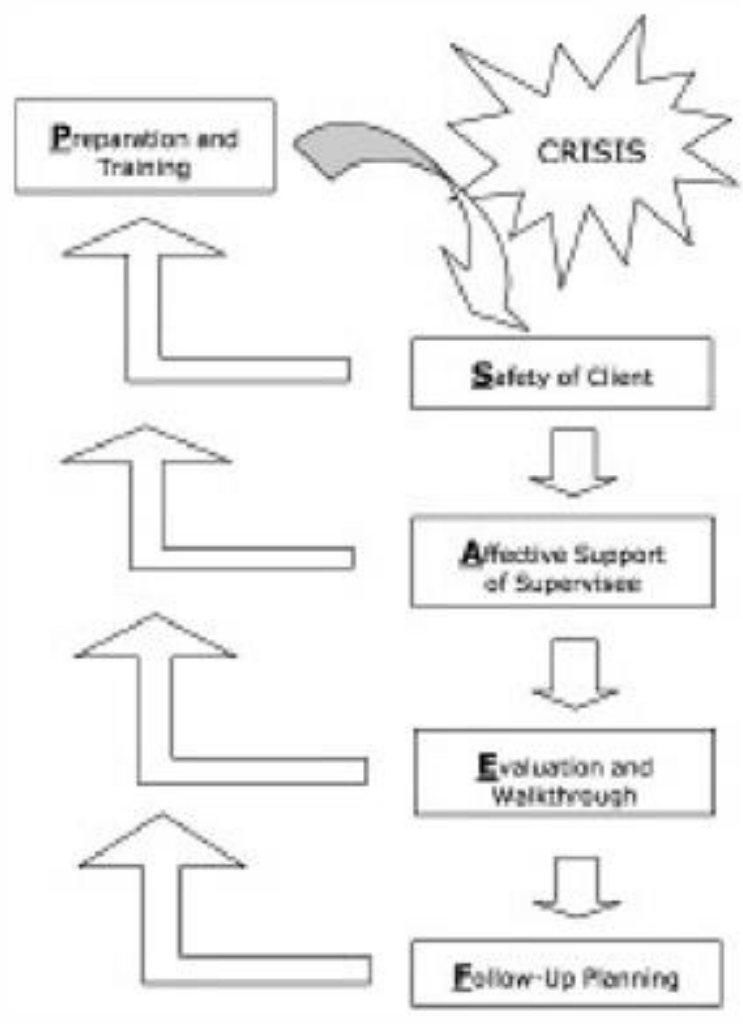

In the previous pages, we proposed a peer supervision model for crisis intervention and we provided steps for ensuring Preparation and training, Safety of client, Affective support for the supervisee, Evaluation and walk-through, and Follow-up planning. This model may be applied in dyads or group supervisory relationships. Next, we present recommendations for beginning and maintaining P-SAEF peer supervision relationships within the school setting.

\section{Practical Recommendations for Implementing P-SAEF}

Although the process of implementing P-SAEF will depend on the specific nature of one's environment, school counselors may find the following suggestions helpful for beginning and maintaining crisisspecific peer supervision. First, successful implementation of P-SAEF depends on the development of crisis-response networks within and beyond the walls of one's school. School counselors may find teams within their own offices, or they may make connections with potential participants through conferences, district counseling meetings, or local mental health agencies. This reaching-out process is especially important for school counselors who are the sole counselor at their locations. The process may reduce isolation and ensure that P-SAEF participants bring a variety of experiences and expertise. After networks are formed, school counselors may advocate for administrative support at the school and district levels. Administrative support might enable school counselors and associated personnel to attend crisis and supervision training workshops (for the Preparation and Training phase) or to have a protected time in which to meet on a biweekly, monthly, or quarterly basis. 
Once interested parties have been identified, it is important to identify preparation and training needs of individual group members. Because individuals implementing the P-SAEF model may have gaps in crisis intervention or supervision training, active participation in the Preparation and Training portion of the P-SAEF model is critical for the model's success. In situations where PSAEF participants are presented with a crisis for which they have limited knowledge and skills, individuals may consult with a crisis intervention specialist at a local crisis facility or with a counselor educator who has expertise in crisis intervention. This consultation can increase participants' knowledge base while facilitating development of crisis-specific networks.

Just as a lack of crisis preparation presents ethical concerns for counselors who are called upon to provide crisis intervention, ethical guidelines of the Association for Counselor Education and Supervision (1993) indicate that counselor supervisors must have formal preparation to provide supervision. Evaluation is essential for ensuring client safety (Bernard \& Goodyear, 2004), yet peer supervisors tend to struggle with challenging supervisees (Benshoff \& Paisley, 1996; Wilkerson, 2006). P-SAEF participants, therefore, may find supervision workshops useful for ensuring ethical provision of services and developing skills necessary to facilitate the Evaluation portion of the model. In addition, participant agreements regarding the nature of the evaluation and feedback process may assist in setting expectations for evaluative feedback.

\section{Future Directions \& Conclusions}

A notable absence of literature related to school counselor crisis intervention and supervision indicates a definite need for research on this topic. Despite the availability of crisis plans and resources for developing crisis plans in schools, the follow-up component of supervision and training is lacking. Although the United States Department of Education (2003) published literature on crisis planning which mentions the various stages of prevention, preparedness, response, and recovery, the document includes no mention of a supervisory process for school counselors. Research regarding the need for crisis supervision in the schools may raise awareness regarding this significant gap in the preparation and supervision of school counselors.

Researchers may also investigate the effectiveness of clinical and peer supervision for school counselors. Finally, researchers may investigate the effectiveness of the P-SAEF model as a foundation for crisis-specific peer supervision.

As discussed in this article, school counselors are called upon to provide expert response to potentially lethal situations. Without proper preparation and supervision, school counselors are left to handle intense crisis situations while providing support to affected students, administration, and staff. The P-SAEF model provides a starting point for discussion while preparing and supporting school counselors within their school communities.

\section{References}

Agnew, T., Vaught, C. C., Getz, H. G., \& Fortune, J. (2000). Peer group clinical supervision program fosters confidence and professionalism. Professional School Counseling, 4, 6-12. 
Allen, M., Burt, K., Bryan, E., Carter, D., Orsi, R., \& Durkan, L. (2002). School counselors' preparation for and participation in crisis intervention. Professional School Counseling, 6, 96102.

American School Counselor Association. (2000). Critical incident response in schools (Position Statement). Alexandria, VA: Author.

American School Counselor Association. (2004). Ethical standards for school counselors. Alexandria, VA: Author.

American School Counselor Association (2005). The ASCA national model: A framework for school counseling programs (2nd ed.). Alexandria, VA: Author.

Association for Counselor Education \& Supervision, Supervision Interest Network. (1993). ACES ethical guidelines for counseling supervisors. ACES Spectrum, 54, 5-8.

Baggerly, J., \& Osborn, D. (2006). School counselors' career satisfaction and commitment: Correlated and predictors. Professional School Counseling, 9, 197-205.

Benshoff, J. M., \& Paisley, P. O. (1996). The structured peer consultation model for school counselors. Journal of Counseling and Development, 74, 314-318.

Bernard, J. M., \& Goodyear, R. K. (2004). Fundamentals of Clinical Supervision (3rd ed.). Boston: Pearson.

Centers for Disease Control and Prevention. (2006). Youth risk behavior surveillance - United States, 2005. Morbidity and Mortality Weekly Report, 55, SS-5. Retrieved November 1, 2006, from http://www.cdc.gov/mmwr/PDF/SS /SS5505.pdf

Crutchfield, L. B., \& Borders, L. D. (1997). Impact of two clinical peer supervision models on practicing school counselors. Journal of Counseling and Development, 75, 219-230.

Culbreth, J. R., Scarborough, J. L., Banks-Johnson, A., \& Solomon, S. (2005). Role stress among practicing school counselors. Counselor Education \& Supervision, 45, 58-71.

DeVoe, J., Peter, K., Kaufman, P., Miller, A., Noonan, M., Snyder, T, et al. (2004). Indicators of school crime and safety: 2004 (NCES 2005-002/NCJ 205290). U.S. Departments of Education and Justice. Washington, DC: U.S. Government Printing Office.

Fong, T. L. (2005). Burnout and psychological health in residential childcare workers of emotionally disturbed children [Abstract] . Dissertation Abstracts, 66(3B), 1715.

King, K. A., Price, J. H., Telljohann, S. K., \& Wahl, J. (1999). How confident do high school counselors feel in recognizing students at risk for suicide? American Journal of Health Behavior, $23,457-467$. 
Kinzel, A., \& Nanson, J. (2000). Education and debriefing: Strategies for preventing crises in crisis-line volunteers. The Journal of Crisis Intervention and Suicide Prevention, 21, 126-145.

Kleespies, P. M., Niles, B. L., Mori, D. L., \& Deleppo, J. D. (1998). Emergencies with suicidal patients: The impact on the clinician. In P. M. Kleespies (Ed.), Emergencies in mental health practice: Evaluation and management (pp. 379-397). New York: Guilford.

Mathai, C. M. (2002). Surveying school counselors via the internet regarding their experiences and training needs in crisis intervention. Unpublished doctoral dissertation, Virginia Polytechnic Institute and State University, Blacksburg, VA.

Miller, G. M., \& Dollarhide, C. T. (2006). Supervision in schools: Building pathways to excellence. Counselor Education \& Supervision, 45, 296-303.

Page, B. J., Pietrzak, D. R., \& Sutton, J. M. (2001). National survey of school counselor supervision. Counselor Education and Supervision, 41, 142-150.

Peace, S. D. (1995). Addressing school counselor induction issues: A developmental counselor mentor model. Elementary School Guidance and Counseling, 29, 177-190.

Schaufeli, W., Marek, T., \& Maslach, C. (1993). Professional burnout: Recent developments in theory and research. New York: Hemisphere Press.

Thomasgard, M. \& Collins, V. (2003). A comprehensive review of a cross-disciplinary, casebased peer supervision model. Families, Systems, \& Health, 21, 305-319.

Tracey, T., Ellickson, J. L., \& Sherry, P. (1989). Reactance in relation to different supervisory environments and counselor development. Journal of Counseling Psychology, 36, 335-344.

U.S. Department of Education, Office of Safe \& Drug-Free Schools. (2003). Practical information on crisis planning: A guide for schools and communities. Washington, DC: Author.

Wachter, C. A. (2006). Crisis in the schools: Crisis, crisis intervention training, and school counselor burnout. Unpublished doctoral dissertation, University of North Carolina at Greensboro, Greensboro, NC.

Westefeld, J. S., Range, L. M., Rogers, J. R., Maples, M. R., Bromley, J. L., \& Alcorn, J. (2000). Suicide: An overview. The Counseling Psychologist, 28, 445-510.

Wilkerson, K. (2006). Peer supervision for the professional development of school counselors: Toward an understanding of terms and findings. Counselor Education \& Supervision, 46, 59-67.

Wood, C., \& Rayle, A. D. (2006). A model of school counseling supervision: The goals, functions, roles, and systems model. Counselor Education \& Supervision, 45, 253-266. 
